\title{
Planning health care for patients with Graves' orbitopathy
}

\author{
Inna V. Sasim • Tos T. J. M. Berendschot • \\ Chantal van Isterdael • Maarten P. Mourits
}

Received: 11 December 2007 /Revised: 29 March 2008 / Accepted: 2 April 2008 / Published online: 26 June 2008

(C) The Author(s) 2008

\begin{abstract}
Background To describe disease parameters of patients with Graves' orbitopathy in a tertiary referral center in order to plan health care resource allocations. To investigate whether the clinical activity and/or the severity of the disease can be used as a predictor of the duration of treatment.

Methods Retrospective, observational, non-comparative case series. One hundred and seventeen charts of GO-patients, randomly chosen out of a pool of 1600, referred to the Orbital Unit of the University Medical Centre Utrecht between 1 January 1992 and 1 January 2002, were analysed. Relevant parameters, such as age, gender, race, disease duration, smoking habits, concomitant diseases, previous treatment, symptoms and signs, number and sort of investigations, severity and activity scores, number and sort of treatments, treatment duration and outcome of treatment were retrieved and analysed. Disease activity and severity at entry were tested as possible predictors of disease duration and extent of treatment.
\end{abstract}

The authors have no financial interest in any aspect of this study.

I. V. Sasim $\cdot$ C. van Isterdael $\cdot$ M. P. Mourits

Department of Surgical Specialties, Division of Ophthalmology,

University Medical Centre Utrecht,

Utrecht, Netherlands

T. T. J. M. Berendschot

University Eye Clinic Maastricht,

Maastricht, The Netherlands

I. V. Sasim $(\square)$

Department of Ophthalmology,

University Medical Center Utrecht,

Orbital Unit, P.O. Box 85500, E03-136,

3508 GA Utrecht, Netherlands

e-mail: isasim@oogh.azu.nl
Results Clinical profile at presentation; duration of the disease; extent of treatment; predictors of disease duration and of number of treatment interventions were the main outcome measures. Three percent of patients had Only Signs, but No Symptoms (OSNS), 61\% had mild, 27\% had moderately severe and 9\% had severe GO. Fifteen percent had inactive disease at presentation, 65\% had borderline activity and only $20 \%$ had active orbitopathy. Sixty percent complained about eyelid swelling and/or proptosis. The average period of eye treatment was 2.5 years (range: 0 110 months), during which patients were seen at an average of 8 times. Twenty percent needed no treatment at all. Fifteen percent were treated with nothing but lubricants and/or prisms. Twenty-five percent were treated with immunosuppressive modalities. Fifty-six percent underwent one or more surgical corrections. The Clinical Activity Score (CAS) was found to be significantly related to the duration of the treatment $(\mathrm{p}<0.001)$, to the number of visits $(\mathrm{p}<0.001)$, and to the number of surgical interventions $(\mathrm{p}<0.001)$.

Conclusions The majority of GO patients referred to a tertiary referral centre has no or borderline disease activity and 'mild' orbitopathy, disfiguring eyelids and proptosis being the most frequent complaints. The disease activity as assessed with the CAS can be used to predict the duration and extent of the treatment.

Keywords Graves' orbitopathy - Tertiary referral center · Health care $\cdot$ Clinical activity $\cdot$ Severity $\cdot$ Predictor

\section{Introduction}

GO is part of a multi-system auto-immune disorder, including Graves' Thyroid Disease (GTD), Graves' Dermopathy and Graves' Acropachy. [1,2] The incidence of GTD in the 
Dutch population (16 million) is roughly estimated 1:5000, or about 1200 female patients per year. [3] Approximately, $30-60 \%$ of them have ophthalmic/orbital involvement. [4] GO often runs a course independently of GTD. GO is described in terms of severity and activity. [5, 6] The spontaneous course and the different stages of Graves' orbitopathy have been described by Rundle. [7] Active and more severe forms of GO, that do not improve spontaneously, are treated with immunosuppressive modalities. It is common practice, however, to wait for the burnout stage of the disease before rehabilitative surgery, such as proptosis reduction, squint surgery and eyelid correction, is started. GO is a mutilating and often disabling disease, considered more difficult to carry than for instance diabetes mellitus [8]. Thus, there is a strong demand for treatment and the share of GO-patients in an orbital center is considerable. Although the efficacy and safety of individual immunosuppressive and surgical interventions have been described extensively [9, 10], little has been published on the overall management of GO [11]. We were, therefore, interested in the patient's clinical profile at presentation in a tertiary referral centre, the duration of the disease and the number and outcome of treatment interventions of a large cohort of GO-patients. Furthermore, our goal was to define predictors for these items in order to acquire evidence for streamlining a clinic for GO-patients.

We applied two instruments: disease activity and disease severity. Disease activity refers to the stage of the disease. The stage can be assessed using the Clinical Activity Score, which is based on the classical signs of inflammation, such as pain, swelling, redness and impaired function. Ten items can be scored, the sum being the CAS. [5, 6]

To assess disease severity we used a modified NO SPECS classification.

\section{Materials and methods}

The files of all GO-patients, who's family name started with an A or a B, referred to the Orbital Unit of the University Medical Centre Utrecht (UMCU) between 01/01/1992 and $01 / 01 / 2002$, were retrospectively reviewed. Relevant data such as age, gender, race, smoking habits, presence of concomitant diseases and systemic disorders, history and treatment of GTD were collected.

The included patients were divided into four groups of disease severity. For this purpose, we applied a modified NOSPECS classification [12]. We used a modified ZeissJena Hertel exophthalmometer, in which -for the sake of the patient's comfort- the footplate has been softened with rubber rings. Compared to other Hertel meters, this exophthalmometer shows lower readings. We therefore tested this instrument and assessed the upper limits of normal in another study. [13] Consecutively, we adapted the NO SPECS classification in class III (Table 1).

Severity A Only signs (such as eyelid retraction), no symptoms

Severity B NOSPECS class $2 a$ or $b$, and/or $3 a$, and or $4 a$, and/or 5 a

Severity C NOSPECS class $2 c$, and/or $3 b$ or $3 c$, and/or $4 \mathrm{~b}$, and/or $5 \mathrm{~b}$

Severity D NOSPECS class $4 c$, and/or $5 \mathrm{c}$ and/or $6 \mathrm{a}$, or $6 \mathrm{~b}$, or $6 \mathrm{c}$

To group our patients into classes of disease activity, we considered patients with a Clinical Activity Score (CAS) of less than 1 being 'inactive', patients with a CAS of 1 to 3 being borderline and those with a CAS of more than 3 being 'active'. [6]

\section{Statiscical analysis}

All assembled data were entered into a specially designed data base and checked by a medical analyst. The statistical analysis was done with SPSS 14.0 software. To find possible prediction models for the duration of treatment, for the number of investigations, and the numbers of visits, we used a stepwise regression analysis. We used the forward conditional method with default selection criteria, $\mathrm{P}<0.05$ to enter and $\mathrm{P}>0.10$ to remove. In order to correct for their possible mutual influence, we used as independent variables gender, age, complaints and symptoms during the first and last visit, thyroid status, previous treatment and duration of GO and GTD, and the categories for NOSPECS and CAS.

\section{Results}

General characteristics and concomitant diseases at first visit

See Table 2. Hundred and seventeen patients out of 1600 were included. All percentages in the text and tables are valid percentages. Eighty percent of our patients were female. The mean age of all patients was 48 years (range

Table 1 Modified NOSPECS class III. Using a modified Zeiss-Jena exophthalmometer, we redefined class III (exophthalmos) as follows

3 o exophthalmos $\leq 17 \mathrm{~mm}$ for females and $\leq 20 \mathrm{~mm}$ for males

3 a exophthalmos 18 or $19 \mathrm{~mm}$ for females and 21 or 22 for males

$3 \mathrm{~b}$ exophthalmos 20-22 $\mathrm{mm}$ for females and 23-25 $\mathrm{mm}$ for males

$3 \mathrm{c}$ exophthalmos $\geq 23 \mathrm{~mm}$ for females and $\geq 26 \mathrm{~mm}$ for males 
Table 2 General patient characteristics at first visit to tertiary referral centre

\begin{tabular}{llllll}
\hline Age & N & Valid & Mean & Min & max \\
& pts & $\%$ & & & \\
\hline Male + female & & & 49 & 14 & 86 \\
$\quad$ Female & 93 & & 48 & 14 & 86 \\
$\quad$ Male & 24 & & 51 & 24 & 73 \\
Gender & & & & & \\
$\quad$ Female & 93 & 80 & & & \\
Male & 24 & 20 & & & \\
Race & & & & & \\
Asian & 4 & 3 & & & \\
Black & 1 & 1 & & & \\
Caucasian & 112 & 96 & & & \\
Smoking & & & & \\
Yes & 58 & 64 & & \\
No & 33 & 36 & & \\
Concomitant diseases & & & & \\
DM & 8 & 7 & & \\
NHL & 2 & 2 & & \\
Dermopathy & 1 & 0.9 & & \\
Acropathy & 1 & 0.9 & & \\
Other eye diseases & & & & \\
Diabetic retinopathy & 1 & 0.9 & & \\
Cataract & 4 & 3 & & \\
Cataract & 4 & 3 & & \\
ARMD & 1 & 0.9 & & \\
Amblyopia & 1 & 0.9 & & \\
Referred by & & & & \\
$\quad$ General practioner & 12 & 11 & & \\
Ophthalmologist & 63 & 56 & & \\
Other hospital & 9 & 8 & & \\
$\quad$ Own hospital & 21 & 19 & & \\
$\quad$ Own initiative & 4 & 3 & & \\
Second opinion & 4 & 3 & & \\
\hline
\end{tabular}

14-86). There were two teenagers, both female, age 14 and 16. Both had mild, not active GO. Both were treated with lubricants. The one of 16 years old underwent a unilateral levator lengthening. Out of 117 patients, 112 were Caucasian, 4 Asian, and 1 black. Sixty-four percent of patients were cigarette smokers. Eight patients had concomitant diabetes mellitus, 2 were suffering from a non-Hodgkin lymphoma; 1 had vitiligo, 1 had thyroid dermopathy and 1 acropachy. The majority of our patients (56\%) were referred by an ophthalmologist outside our hospital.

\section{Duration before referral, previous treatment}

See Tables 3 and 4. At the time of their first visit to our clinic, $75 \%$ of the patients were suffering from GTD for more than one year. Ninety percent had been treated with block and replacement therapy (thyreostatics and thyroxin), 50\% with thyrostatics only, $34 \%$ with $\mathrm{I}^{\mathrm{I} 1}$, and $12 \%$ had undergone
Table 3 Thyroid parameters at first visit

\begin{tabular}{ccc}
\hline & N pts & Valid \% \\
\hline $\begin{array}{c}\text { Duration of GTD } \\
<1 \text { year }\end{array}$ & 27 & \\
$>1$ year & 81 & 75 \\
Previous treatment & & \\
Thyrostatics & 99 & 90 \\
I131 & 38 & 34 \\
thyroidectomy & 13 & 12 \\
Euthyroid & & \\
Hyperthyroid & 66 & 58 \\
Hypothyroid & 24 & 20 \\
Thyroiditis & 14 & 12 \\
Unknown & 1 & 9 \\
\hline
\end{tabular}

thyroidectomy. Fifty-eight percent of patients were clinically and biochemically euthyroid, $20 \%$ were hyperthyroid, $12 \%$ were hypothyroid, $1 \%$ had thyroiditis (in 9\% the thyroid status could not be retrieved in this material). As we could regain, $49 \%$ had a history of GO shorter and $51 \%$ longer than one year. Previous treatment of GO included lubricants in $30 \%$, radiotherapy in $8 \%$, oral prednisone in $15 \%$, intravenous prednisone in 3\%. Fifteen patients out of 117 had undergone some kind of surgery in connection to their GO; 7 of them had undergone an orbital decompression.

GO symptoms and sign

See Table 5.

\section{Complaints}

Being unhappy with their looks (eyelid swelling: 49\%, disfiguring proptosis: $(44 \%)$, diplopia (45\%), tearing $(45 \%)$, retrobulbar pain in rest or during eye movements (40\%), and photophobia (33\%) were the most frequent complaints, followed by blurred vision $(25 \%)$ and feeling of grittiness (19\%).

Table 4 Eye parameters at first visit

\begin{tabular}{ccc}
\hline & N pts & valid \% \\
\hline $\begin{array}{c}\text { Duration of GO } \\
<1 \text { year }\end{array}$ & 52 & 49 \\
$>1$ year & 55 & 51 \\
Previous treatment & & \\
Lubricants & 35 & 30 \\
Oral Prednisone & 17 & 15 \\
I.V. Prednisone & 3 & 3 \\
Radiotherapy & 9 & 8 \\
\hline
\end{tabular}


Table 5 Ophthalmic findings in 117 GO patients at first visit to tertiary referral centre

\begin{tabular}{|c|c|c|}
\hline & $\mathrm{N}$ & Valid percent \\
\hline Retrobulbar pain & 47 & 40 \\
\hline Tearing & 53 & 45 \\
\hline Photophobia & 38 & 33 \\
\hline Grittiness & 22 & 19 \\
\hline Double vision & 53 & 45 \\
\hline Blurred vision & 29 & 25 \\
\hline Unhappy with eyelids & 57 & 49 \\
\hline Unhappy with proptosis & 52 & 44 \\
\hline Lid aperture $>10 \mathrm{~mm}$ & 80 & 76 \\
\hline Eyelid swelling & 75 & 65 \\
\hline Eyelid redness & 12 & 10 \\
\hline Chemosis & 34 & 30 \\
\hline Conjunctival redness & 29 & 25 \\
\hline Canuncle swelling & 17 & 15 \\
\hline Superior Limbic keratitis & 1 & 1 \\
\hline Corneal stippling & 12 & 10 \\
\hline Normal VA & 98 & 84 \\
\hline Reduced VA due to GO & $8 / 6$ & $7 / 5$ \\
\hline Reduced VA due to other causes & $10 / 12$ & $9 / 10$ \\
\hline Hertel $>$ ULN, males & 52 & 58 \\
\hline Hertel $>$ ULN, females & 13 & 57 \\
\hline No diplopia & 58 & 52 \\
\hline Diplopia in extremes of gaze & 35 & 31 \\
\hline Diplopia in all directions & 19 & 17 \\
\hline Enlarged muscles on $\mathrm{CT}$ & $16 / 18$ & $25 / 29$ \\
\hline Increased fat volume & $8 / 11$ & $13 / 11$ \\
\hline Increase muscle + fat & $28 / 28$ & $45 / 45$ \\
\hline Apical crowding & $2 / 3$ & $3 / 5$ \\
\hline No abnormalities & $9 / 7$ & $14 / 11$ \\
\hline
\end{tabular}

When two numbers are given per item, the first refers to the right and the second to the left eye. When one number per item is given, this number refers either to the patient or to the eyes, in which the findings in $\mathrm{OD}$ and $\mathrm{OS}$ were exactly similar. $\mathrm{OD}=$ Right eye, $\mathrm{OS}=$ Left Eye

\section{Signs \& symptoms}

A best corrected visual acuity of less than 0.8 on the Snellen chart, presumably due to GO, was found in $7 \%$ of our patients. The average Hertel value of the worst eye, using our modified Zeiss-Jena exophthalmometer was $17.8 \mathrm{~mm}$ (range:10-27, SD: $3.4 \mathrm{~mm}$ ), the average for females being 17.3, SD: $3.4 \mathrm{~mm}$ and for males 19.7, SD: $3.2 \mathrm{~mm}$ ). Fifty-eight percent of the male and $57 \%$ of the female patients had Hertel values above the upper limit of normal in relationship to the modified Zeiss-Jena Hertel we used. The average lid aperture was almost $12 \mathrm{~mm}$ (range: 3 to 18 , SD: $2.7 \mathrm{~mm}$ ). Considering $10 \mathrm{~mm}$ the upper limit of normal for the eyelid aperture in Caucasians, $76 \%$ of the Caucasian patients had an abnormally enlarged palpebral fissure. Fifty-two percent of our patients had normal eye movements and no diplopia in any position of gaze, $31 \%$ had diplopia in extremes of gaze and $17 \%$ had diplopia in primary and reading position. Measurement of eye movements in secondary positions of gaze with a modified perimeter [14] showed an average of elevation of $25^{\circ}$ (342, SD:9.5 $5^{0}$, of depression of $54^{0}\left(30-64, \mathrm{SD}: 8.1^{0}\right)$ of abduction of $41^{0}\left(18-50\right.$, SD:7.8 $\left.8^{\circ}\right)$ and of adduction of $45^{\circ}$ (28-58, SD:5.6 ${ }^{0}$ ) (Numbers refer to the right eye; ductions in the left eyes were comparable). Chemosis was present in $30 \%$, caruncle swelling in $15 \%$, corneal involvement in $10 \%$ of patients.

In 63 patients $(54 \%)$ a CT-scan was made at the first clinical examination. Nine of them (14\%) had a normal scan. Enlargement of the extraocular muscles was seen in $28 \% / 29 \%$ (right eye/left eye), of retrobulbar fat in $13 \% /$ $11 \%$, of the extraocular muscles and fat in $44 \% / 44 \%$. Apical crowding was found in 3 patients.

\section{Dysthyroid Optic Neuropathy (DON)/Additional investigations}

Additional tests for visual functions were only performed in patients with suspected DON ( $\mathrm{n}=27)$. Out of 117 patients, 9 (6 females, 3 males, mean age: 54.7 ) were considered to have DON. Four had bilateral and 5 unilateral DON. The visual acuity in the "DON-eye" varied from $0.4-0.63$. All but one had a CAS of $>3 ; 3$ had apical crowding; all but one had Hertel values of less than $21 \mathrm{~mm}$. Colour vision, visual fields and VEP did not always correlate to the decrease of the visual acuity. All were treated with prednisone (oral and/or I.V.) with or without retrobulbar irradiation and followed by orbital decompression in 2 . At the end of treatment, the CAS was $\leq 1$ in all. Full recovery of visual acuity was seen in 9 DON-eyes.

\section{Treatment}

Twenty percent underwent no treatment at all. Fifteen percent were treated with nothing but lubricants and/or prisms. Twenty-nine patients $(25 \%)$ were treated with (a combination of) immunosuppressive treatment. Of those, 13 patients were treated with prednisone orally, 10 with prednisone intravenous, 15 with orbital irradiation, and 1 patient with cyclosporine (9 received some kind of a combination of these). Radiotherapy was applied in patients with active disease and severe motility impairment.

More than half of all patients $(56 \%)$ required surgical interventions. Twenty-five patients (21\%) underwent orbital decompression $(9 \%$ by a lid/conjunctiva -2 wall and $12 \%$ by coronal -3 wall approach). Strabismus was corrected in 25 patients (21\%). Eyelid lengthening (upper and/or lower, with and without implants) was done in 44 patients (38\%). Blepharoplasty (upper and lower lids) was performed in 35 patients (32\%) (Table 6). 
Table 6 Treatment in our centre

\begin{tabular}{lcc}
\hline Treatment UMCU & N pts & valid \% \\
\hline No treatment & 23 & 20 \\
Lubricants & 63 & 54 \\
Oral Prednisone & 13 & 11 \\
IV Prednisone & 10 & 9 \\
Cyclosporine & 1 & 1 \\
Radiotherapy & 15 & 13 \\
Any surgery & 65 & 56 \\
Decompression & 25 & 21 \\
Strabismus surgery & 25 & 21 \\
Eyelid lengthening upper/lower & 44 & 38 \\
Blepharoplasty upper/lower & 35 & 32 \\
\hline
\end{tabular}

Classification and course

Using our modified NOSPECS classification, 3\% of the included patients had type A GO (only signs, no symptoms), $61 \%$ had type B (mild GO), 27\% had type C (moderately severe), 9\% had type D (severe GO). Eight percent had DON at their first visit. Among the patients with a history of GO of more than one year, 9 patients had inactive, 39 borderline activity and 7 active orbitopathy. Among those with a GO history of less than one year, these numbers were 8, 29 and 15 respectively.

Independently from the treatment, the severity of GO increased in 5\%, did not change in 52\% and improved in $43 \%$. (Table 7). 'Inactive GO' $(\mathrm{CAS}<1)$ was assessed in $15 \%$, 'borderline activity' (CAS $1-3$ ) in $65 \%$ and 'active' $(\mathrm{CAS}>3)$ in $20 \%$. Seventy-eight percent had OSNS, mild or moderate orbitopathy with a CAS of less than 4 . Of all patients, less then 1 percent of patients deteriorated, $35 \%$ remained stable and $64 \%$ improved in terms of activity (Table 8). Of those, who were managed without immunosuppressive or surgical treatment $(\mathrm{N}=40), 1$ inactive patient (3\%) developed borderline activity; 1 patient (3\%) with

Table 7 Cross-table showing severity of GO (worst eye) according to the modified NOSPECS classification at first and last visits (numbers of patients)

\begin{tabular}{lrrrrrr}
\hline & \multicolumn{1}{c}{ NOSPECS last visit } & & Total \\
\hline NOSPECS 1st visit & & \multicolumn{1}{c}{ A } & B & C & D & \\
& A & 3 & 1 & 0 & 0 & 4 \\
& B & 17 & 49 & 4 & 0 & 70 \\
& C & 5 & 18 & 7 & 1 & 33 \\
& D & 0 & 5 & 4 & 1 & 10 \\
& & 25 & 73 & 15 & 2 & 115 \\
\hline
\end{tabular}

Deteriorations in red. Improvement in blue. So, four patients had class A at first visit. Of those 4, at the last visit, one had class $\mathrm{B}$, one class $\mathrm{C}$ and zero class D.
Table 8 Cross-table showing activity of GO (worst eye) according to the CAS classification at first and last visits (numbers of patients)

\begin{tabular}{lllllr}
\hline \multicolumn{3}{c}{ CAS, last visit } & & \multicolumn{2}{c}{ Total } \\
\hline CAS 1st & & Inactive & Borderline & Active & \\
visit & Inactive & 16 & 1 & 0 & 17 \\
& Borderline & 50 & 23 & 0 & 73 \\
& Active & 16 & 7 & 0 & 23 \\
& & 82 & 31 & 0 & 113 \\
\hline
\end{tabular}

Deterioration in red. Improvement in blue.

OSNS developed mild GO and three (8\%) with mild GO developed moderately severe GO.

Duration of the treatment

The average duration of treatment was 28 months (range 0 110, SD:25.4 months). An "average patient" visited our hospital 8 times (range: 1-37, SD:6.6) and underwent 0.5 (range 0-3, SD:0.9) operations under general and 0.8 (range 0-4, SD:1.0) corrections in local anaesthesia.

\section{Prediction}

Regression analysis showed a significant relationship between the CAS value and the duration of the treatment $(p<0.001)$, between the CAS value and the number of visits $(p<0.001)$ and between the CAS value and the number of surgical interventions $(p<0.001)$. No significant correlation could be found between these items and the severity of the disease at first visit as expressed in the Total Eye Score (TES) [15].

\section{Comparison of subgroups}

For the study, we defined smokers as those who were still smoking at the time of referral or those who had stopped smoking less than 12 months ago. All others were considered non-smokers. Comparing the subgroup of smokers with non-smokers, we found a significant difference in the severity at the moment of referral. Smokers had more proptosis $(\mathrm{p}=0.04)$ and more motility impairment $(\mathrm{p}=$ 0.03 ). No significant differences between the two subgroups could be assessed as for the total number of visits to our clinic or for the duration of the disease or for the number of interventions.

Comparing the subsets of patients who had had major interventions (such as immunosuppressive treatment or surgery) before referral to our centre with those who had had no other treatment than lubricants, we found no significant differences in severity, outcome and disease duration.

Comparing the subgroups of patients who had I ${ }^{131}$ treatment before or during their eye treatment in our 
institution with those who never have been treated with I ${ }^{131}$ we found no significant differences in severity and outcome.

\section{Discussion}

This is a retrospective study, in which we use valid percentages because not all data of each included patient were available. For instance, the CAS at first visit had not been described in 4 out of 117 patients and the NO SPECS classification could not be retrieved in 2 patients. The referral pattern to our unit may not be identical for other orbital centres in the world. These limitations have to be taken into account. Our findings confirm earlier studies regarding the female preponderance in $\mathrm{GO}$, the age distribution, and presenting symptoms. [1, 2] In accordance with previous studies, almost $60 \%$ of our patients had exophthalmometry values above the upper limit of normal. Considering $10 \mathrm{~mm}$ the upper limit of normal for the eyelid aperture in Caucasians, $76 \%$ of all patients had an abnormally enlarged palpebral fissure. Thus, proptosis together with eyelid retraction is the most common presentation of GO at our unit.

At the time of referral to our centre, $51 \%$ of the patients had orbitopathy for more than 12 months and in $75 \%$ the diagnosis of dysthyroidism had been made more than one year before. In spite of these considerable delays, $20 \%$ of the referred patients were still hyper- and $12 \%$ hypothyroid, indicating the difficulty to achieve euthyroidism in some Graves patients. Rendering a patient euthyroid, however, is of utmost importance as it may be beneficial to the ocular status as well. [16] The prevalence of active disease (CAS> 3 ) among patients with a GO duration of less than one year was more than twice as much as among those with a GO duration of more than one year $(p=0.055)$. However, $13 \%$ of the last group still had active GO, indicating that disease duration and disease activity are not interchangeable. Ninety percent of our patients had been treated with thyrostatics and only $34 \%$ with radioactive iodine. These percentages are more or less similar with other European centres [14], but differ from those in North-America [2], reflecting the popularity of $\mathrm{I}^{131}$ in the treatment of hyperthyroidism in the latter countries. The prevalence of smokers in our study group (64\%) is clearly higher than in other studies (54\%) [2] and (40\%) [17]. Although smoking is considered a risk factor for the development of severe GO [18], in our series we could not find a significant correlation between smoking and severity (as expressed in the NOSPECS- classification) or activity of GO ( $p=0,71$ and $p=0,52$ ). However, smokers were found to be more proptosed and to have more motility impairment than nonsmokers at the time of referral. Moreover, out of 9 patients with DON, 6 were smokers and out of 22 patients with a
CAS $>3,16$ were current smokers. A diagnosis of DON is sometimes difficult to make, as the condition is not well defined. We considered 9 patients $(8 \%)$ to have DON. It was striking that all but one of these patients had high CAS-values. Some kind of surgery was eventually carried out in $56 \%$ of our patients. This number is high and may reflect the long history of rehabilitative orbital decompression in the Netherlands.

In general, the clinical presentation of GO varies from minimal eyelid swelling and retraction to disfiguring proptosis, severe motility restriction and reduced vision due to a corneal ulcer or optic nerve compression. However, the GO patients seen at our tertiary referral center, basically fall into two categories. The patient most frequently seen was a middle aged woman with a history of GTD of more than one year and with non-active eye disease consisting of eyelid alterations and proptosis and sometimes limitation of motion in the extremes of gaze (Category I). The orbitopathy they have we call "mild" or moderately severe, because vision is normal and there is no significant diplopia. However, these patients themselves do not consider their disease "mild", as they may be handicapped by tearing and irritation and last but not least by the social implications of their changed looks. We believe a CT scan in this group is only required when the diagnosis cannot be made on the clinical picture alone or when orbital decompression is planned. The chance to deteriorate in this subgroup is small. In our patients the chance to deteriorate for those who didn't receive treatment other than local measures was 11 percent and the deterioration was very modest. These patients can thus safely prescribed local measures and return after three months. Then, when the clinical findings are stable, they return to their referents or are planned for eyelid surgery (lengthening with or without blepharoplasty in local anaesthesia) or for orbital decompression followed by accessory surgery (squint and/or eyelid surgery), if required.

The second category, approximately one-third of patients (36\%) have more severe forms of GO. More than half of these patients have active disease (e.g. CAS $>3$ ). Older men are relatively frequent in this group. Their symptoms vary from severe proptosis to motility restriction causing diplopia and to reduced vision. To follow their disease development, repeated ophthalmic, orthoptic and even CT scans are required. Depending on the severity and the activity of the disease, treatment options are immunosuppressive therapy or acute orbital decompression. In our clinic, we reserve orbital decompressions for those, who do not respond to immunosuppressive treatment. In case of suspected optical nerve involvement, additional testes are performed (colour vision, visual field, VEP). If the CAS is low or has become low after immunosuppressive treatment (needed in approximately 1 out of 4 GO patients), these patients are rehabilitated surgically just as category I patients. 
As patients with active orbitopathy, in contrast to patients with inactive disease, require not only rehabilitative surgery, but previous immunosuppressive treatment as well, activity of the disease at entry is the most important predictor of the disease duration, the number of visits and of interventions, as demonstrated by our findings.

This study allows us to estimate the logistic consequences and treatment planning of a GO-patient at a tertiary referral centre. Twenty-five percent of patients needs RT or immune-suppressive treatment; 20 percent needs orbital decompression, the same percentage squint surgery and 40 percent eyelid surgery. An average of 8 controls is necessary. The total duration of the eye treatment is 2.5 years. With these data, patients can be informed about the number and kind of interventions they can expect and the duration of their social and functional disability.

Open Access This article is distributed under the terms of the Creative Commons Attribution Noncommercial License which permits any noncommercial use, distribution, and reproduction in any medium, provided the original author(s) and source are credited.

\section{References}

1. Burch HB, Wartofsky L (1993) Graves'ophthalmopathy: current concepts regarding pathogenesis and management. Endocr Rev 14:747-793

2. Bartley GB, Fatourechi V, Kardmas EF, Jacobsen SJ, Ilstrup DM, Garrity JA, Gorman CA (1995) The incidence of Graves' ophthalmopathy in Olmsted County, Minnesota. Am J Ophthalmol 120:511-517

3. Gerding MN (1999) Assessment of disease activity in Graves' ophthalmopathy. L van der Velde, Deventer, NL, pp 13-15

4. Gamblin GT, Harper DG, Galentine P, Buck DR, Chernow B, Eil C (1983) Prevalence of increased intraocular pressure in Graves' disease: Evidence of frequent subclinical ophthalmopathy. N Engl J Med 308:420-424

5. Mourits MP, Koornneef L, Wiersinga WM, Prummel MF, Berghout A, vd Gaag R (1989) Clinical criteria for the assessment of disease activity in Graves' ophthalmopathy: a novel approach. Br J Ophthalmol 73:639-644

6. Mourits MP, Prummel MF, Wiersinga WM, Koornneef L (1997) Clinical activity score as a guide in the management of patients with Graves' ophthalmopathy. Clin Endocrinol (Oxf) 47:9-14 (Erratum in: Clin Endocrinol (Oxf) 1997;47:632)

7. Rundle FF, Pochin EE (1944) The orbital tissues in thyrotoxicosis: a quantitative analysis relating to exophthalmos. Clin Sci 5:51-74

8. Terwee CB, Dekker FW, Prummel MF, Wiersinga WM (2001) Graves' ophthalmopathy through the eyes of the patient: a state of the art on health-related quality of life assessment. Orbit 20:281-290

9. Bartalena L, Marcocci C, Tanda ML, Piantanida E, Lai A, Marino M, Pinchera A (2005) An update on medical management of Graves' ophthalmopathy. Review. J Endocrinol Investig 28:469-478

10. Morax S, Ben Ayed H (2004) Orbital decompression for dysthyroid orbitopathy: a review of techniques and indications. $\mathrm{J}$ Fr Ophtalmol 27:828-844

11. Bartley GB, Fatourechi V, Kadrmas EF, Jacobsen SJ, Ilstrup DM, Garrity JA, Gorman CA (1996) The treatment of Graves' ophthalmopathy in an incidence cohort. Am J Ophthalmol 121:200-206

12. Werner SC (1969) Classification of the eye changes of Graves' disease. J Clin Endcrinol Metab 29:982-984

13. Mourits MP, Lombardo SH, van der Sluijs FA, Fenton S (2004) Reliability of exophthalmos measurement and exophthalmometry value distribution in a healthy Dutch population and in Graves' patients. An exploratory study. Orbit 23:161-168

14. Mourits MP, Prummel MF, Wiersinga WM, Koornneef L (1994) Measuring eye movements in Graves ophthalmopathy. Ophthalmology 101:1341-1346

15. Prummel MF, Mourits MP, Berghout A, Krenning EP, van der Gaag R, Koornneef L, Wiersinga WM (1989) Prednisone and cyclosporine in the treatment of severe Graves' ophthalmopathy. N Engl J Med 321:1353-1359

16. Prummel MF, Wiersinga WM, Mourits MP, Koornneef L, Berghout A, van der Gaag R (1990) Effect of abnormal thyroid function on the severity of Graves' ophthalmopathy. Arch Intern Med 150:1098-1101

17. Prummel MF, Bakker A, Wiersinga WM, Baldeschi L, Mourits MP, Kendall-Taylor P, Perros P, Neoh C, Dickinson AJ, Lazarus JH, Lane CM, Heufelder AE, Kahaly GJ, Pitz S, Orgiazzi J, Hullo A, Pinchera A, Marcocci C, Sartini MS, Rocchi R, Nardi M, Krassas GE, Halkias A (2003) Multi-center study on the characteristics and treatment strategies of patients with Graves' orbitopathy: the first European Group on Graves' Orbitopathy experience. Eur J Endocrinol 148:491-495 May

18. Krassas GE, Wiersinga W (2006) Smoking and autoimmune thyroid disease: the plot thickens. Eur J endocrinol 154:777-880 